\title{
Analisis Video Comments to Video Likes Ratio Instagram Pada 5 Klub SepakBola Terpopuler Di Indonesia
}

\author{
Tri Yovandi Kurniawan \\ triyovandikrnwn@gmail.com
}

\begin{abstract}
Abstrak
Teknologi informasi dan komunikasi saat ini telah berkembang sangat pesat yang menjadikan masyrakat memiliki cara lain untuk berkomunikasi melalui media social. Penelitian ini menggunakan metode eksploratif kuantitatif untuk mengetahui kredibilitas dari performa akun Instagram 5 klub sepakbola terpopuler di Indonesia. Metode eksploratif merupakan salah satu jenis penelitian sosial yang tujuannya untuk memberikan sedikit definisi atau penjelasan mengenai konsep atau pola yang digunakan dalam penelitianDari kelima akun Instagram 5 Klub SepakBola Terpopuler Di Indonesia. peneliti menemukan nilai dari masing-masing variable yang ada untuk menghitung rasio Video Comments to Video Likes dari setiap akun. Hasil dari penelitan social media Instagram ini menunjukan bahwa 14 rasio yang dapat digunakan untuk menilai, mengukur, serta membandingkan kredibilitas dari sebuah akun Instagram.
\end{abstract}

Kata Kunci : Media sosial, Instagram, rasio Instagram, kredibilitas akun social media.

\begin{abstract}
Information and communication technology is currently developing very rapidly which makes people have other ways to communicate through social media. This study uses a quantitative exploratory method to determine the credibility of the Instagram account performance of the 5 most popular football clubs in Indonesia. The exploratory method is one type of social research whose purpose is to provide a little definition or explanation of the concepts or patterns used in research from the five Instagram accounts of the 5 Most Popular Football Clubs in Indonesia. the researcher found the value of each of the existing variables to calculate the ratio of Video Comments to Video Likes from each account. The results of this Instagram social media research show that there are 14 ratios that can be used to assess, measure, and compare the credibility of an Instagram account.
\end{abstract}

Keywords : Social media, Instagram, Instagram ratio, credibility of social media accounts. 


\section{PENDAHULUAN}

Teknologi informasi dan komunikasi saat ini telah berkembang sangat pesat yang menjadikan masyrakat memiliki cara lain untuk berkomunikasi melalui media social. Media social memberikan dampak yang besar, masyarakat saat ini menjadikan media social sebagai sarana komunikasi dan juga sebaagai media untuk mendapatkan suatu informasi ataupun menyampaikan informasi. Dengan dampak tersebut membuat aktifitas keseharian masyarakat saat ini menjadi lebih mudah.

Perkembangan yang sangat pesat pada teknologi media social telah memberikan dampak terhadap penyampaian informasi dan juga bahkan komunikasi, saat ini sudah banyak social media yang digunakan untuk menyampaikan informasi dan juga berkomunikasi, salah satunya yaitu Instagram. Instagram sendiri diluncurkan pada tahun 2010 oleh perusahaan yang bernama Burbn, Inc. Instagram merupkan salah satu media sosial untuk berbagi foto dan video, bahkan saat ini instagram sudah memiliki banyak fitur seperti instastory, direct message, IGTV, dll (Agianto, Setiawati, and Firmansyah 2020).

Di Indonesia, terdapat 93 juta pengguna aktif Instagram ("Inilah Negara Pengguna Instagram Terbanyak, Indonesia Urutan Berapa? | Databoks" n.d.). Dengan besar nya jumlah pengguna Instagram aktif di Indonesia tentu dapat memberikan peluang bagi brand untuk menjadikan Instagram sebagai platform social media marketing and information. Cukup banyak akun klub sepakbola di Indonesia yang terdapat pada Instagram. Adapaun 5 klub sepakbola terpopuler di Indonesia, diantaranya yaitu : Persija Jakarta, Persib Bandung, Arema Fc, Persebaya Surabaya, Persipura Jayapura. (“AFC Sebut 5 Klub Terpopuler Di Indonesia, Ada Persija Dan Persib? - Semua Halaman - Bolasport.Com” n.d.)

Penelitian ini menggunakan metode eksploratif kuantitatif, dan akan menghitung menggunakan rasio-rasio yang ada pada Instagram. Pada penelitian (Hendika Permana 2021) menjelaskan bahwa terdapat 14 rasio pada sosial media instagram yang relevan digunakan sebagai media ukur kredibilitas akun yang ada. Penelitian ini hanya berfokus untuk menghitung kredibilitas Video Comments to Video Likess Ratio pada 5 Klub SepaKBola Terpopuler di Indonesia. Tujuan dari penelitian ini adalah mengetahui kredibilitas performa dari akun Instagram 5 Klub SepaKBola Terpopuler di Indonesia menggunakan Video Comments to Video Likess Ratio.

\section{TINJAUAN PUSTAKA}

Perkembangan teknologi yang terjadi saat ini begitu pesat. Banyak aplikasi dan platform media social yang bermunculan, seperti Instagram, Whatsapp, Facebook, dan lain sebagainya. Yang menggunakan aplikasi social media ini tidak hanya kalangan 
remaja saja, bahkan orang tua serta anak-anak juga sudah aktif menggunakan aplikasiaplikasi social media tersebut.

Instagram merupakan aplikasi social media yang dapat digunakan untuk mengembangkan atau menjaga brand dari sebuah perusahaan, influencer, maupun organisasi lainnya. Peran instagram dalam industri makin dirasa penting karena tidak hanya brand yang dapat dibangun, aktifitas lainnya yang dapat dilakukan adalah implementasi marketing. (Hendika Permana 2021). Pada aplikasi Instagram pemilik akun dapat mengunggah foto dan video yang menarik untuk meningkatkan brand yang sedang dikembangkan pada akun tersebut.

Instagram yang semakin dirasakan memiliki kekuatan ataupun pengaruh dalam industri menimbulkan yaitu kualitas akun yang menentukan strata maupun kredibilitas pemilik akun(Hendika Permana 2021). mulai banyak unggahan konten di Instagram yang biasa disebut microblog atau microblogging, yang merupakan penyusunan konten tentang informasi singkat seperti blog mengenai sebuah topik (Jiwantono, Natadjaja, and SALAMOON 2021).

Mudahnya cara penggunaan aplikasi Instagram membuat pengguna menjadikan Instagram sebagai media informasi untuk memenuhi kebutuhannya(Ayutiani and Satria Putri 2018). sehingga Banyak akun klub sepak bola yang menggunakan aplikasi social media Instagram untuk memberikan informasi seputar klub tersebut untuk membuat penggemarnya merasa lebih dekat dengan klub sepak bola idolanya. 


\section{METODE PENELITIAN}

Penelitian ini menggunakan metode eksploratif kuantitatif untuk mengetahui kredibilitas dari performa akun Instagram 5 klub sepakbola terpopuler di Indonesia. Metode eksploratif merupakan salah satu jenis penelitian sosial yang tujuannya untuk memberikan sedikit definisi atau penjelasan mengenai konsep atau pola yang digunakan dalam penelitian("Penelitian Eksploratif - Wikipedia Bahasa Indonesia, Ensiklopedia Bebas" n.d.).

Tujuan dari penelitian ini yaitu mengetahui nilai kredibillitas dari performa akun Instagram 5

Klub SepakBola Terpopuler di Indonesia. Ada beberapa langkah yang harus dilakukan dalam penelitian ini, sehingga mampu menemukan peringkat pertama akun Instagram Klub SepakBola Terpopuler di Indonesia yang memiliki performa terbaik. Langkahlangkah yang dilakukan pada penelitian ini, diantaranya yaitu :

1) Menentukan Eksplorasi Pada Website Untuk Menentukan Objek Yang Akan Dianalisa.

Eksplorasi ini dilakukan pada beberapa halaman website yang menyediakan informasi mengenai objek yang akan di teliti. Setelah eksplorasi selesai, sehingga ditemukan nama-nama Klub SepakBola Terpopuler di Indonesia yang akan dijadikan objek analisa. Setelah melakukan eksplorasi pada halaman website, maka langkah selanjutnya yaitu mencari nama akun Instagram dari masing-masing Klub SepakBola tersebut. Pastikan semua Klub SepakBola memiliki akun pada aplikasi sosial media Instagram.

\section{2) Menghitung Nilai Rata-Rata Variable Dari 5 Klub SepakBola Terpopuler}

\section{Di Indonesia}

Pada langkah ini, peneliti menghitung nilai variable video comments dan variable video likes. Variabel merupakan sesuatu yang memiliki nilai bervariasi dimana nilai tersebut dapat dijadikan sebagai dasar untuk empat data yang berbeda seperti rasio, skala, ordinal, nominal dan internal (Hendika Permana 2021) . Untuk menghitung nilai rata-rata dari variabel video comments dan variabel video likess yaitu dengan cara mengambil 5 postingan kemudian di hitung sehingga menemukan nilai rata-rata dari masing-masing variabel. 


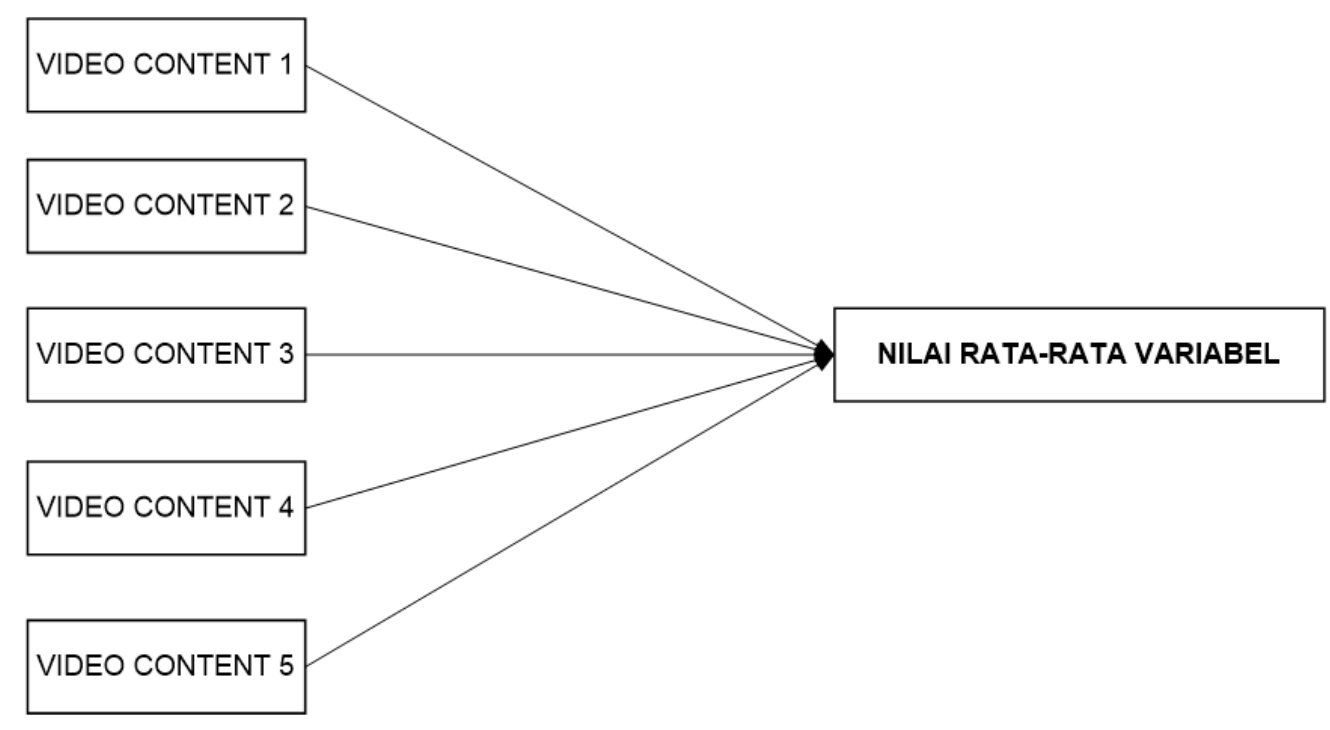

Gambar 1. Analisa Nilai Rata-Rata Variabel

\section{3) Menghitung Nilai Kredibilitas Rasio}

Untuk menghitung nilai kredibilitas dari video comments to video likes ratio, peneliti menggunakan cara membagi nilai variabel pertama dengan nilai variabel kedua. Jika video comments memiliki nilai 200 dan video likes memiliki nilai 400, maka cara menghitungnya yaitu $200: 400=0,5$. Dengan begitu nilai dari video comments to video views ratio adalah 0,5 .

\section{4) Menentukan Peringkat Pada Akun Instagram}

pada langkah terakhir yaitu menentukan peringkat pada masing-masing rasio yang ada. pada penentuan peringkat perlu melihat karakteristik dari rasio yang di teliti. Bila karakteristik rasio ialah rendah, maka objek yang memiliki nilai terendah akan mendapatkan angka 5 serta objek yang memiliki nilai tertinggi akan mendapatkan angka 1. tetapi Bila rasio memiliki karakteritik tinggi maka objek yang menerima nilai tinggi akan mendapatkan angka 5 serta objek yg menerima nilai terendah akan mendapatkan angka 1. setelah mendapatkan hasil kredibilitas ratio maka dapat disimpulkan objek yang mana mendapatkan peringkat 1 sampai dengan peringkat 5 . 


\section{HASIL DAN PEMBAHASAN}

Akun Instagram dari 5 Klub Terpopuler Di Indonesia :

\section{Persija Jakarta}

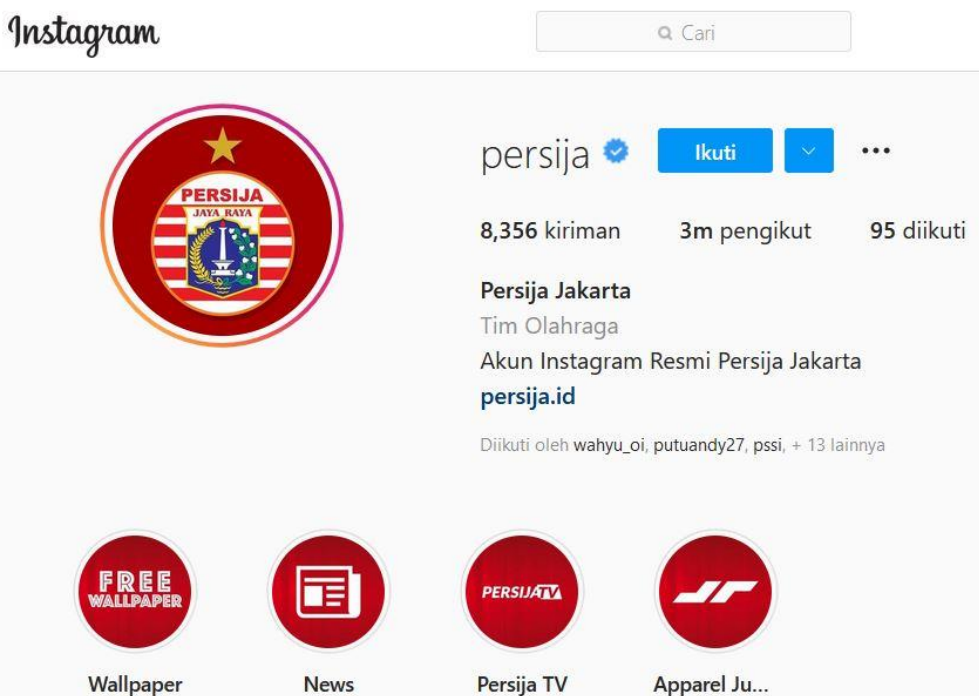

Gambar 2. Akun Instagram Persija Jakarta

Sumber : https:/www.instagram.com/persija/ (akses pada 19-10-2021)

\section{Persib Bandung}

Instagram
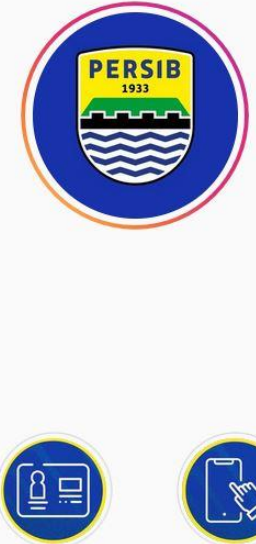

MEMBERSIB

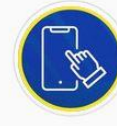

wallpaPERS...

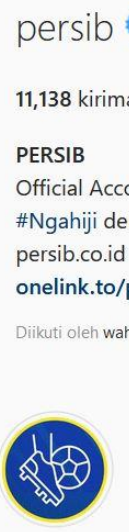

TRAINING

rsib.co.id a Cari

\section{lkuti}

$4.8 \mathrm{~m}$ pengikut

90 diikut

of PERSIB

iji demi Menang Bersama

link.to/persibapp

Gambar 3. Akun Instagram Persib Bandung

Sumber : https:/www.instagram.com/persib/ (akses pada 19-10-2021)
ก (2) 0 


\section{Persebaya Surabaya}

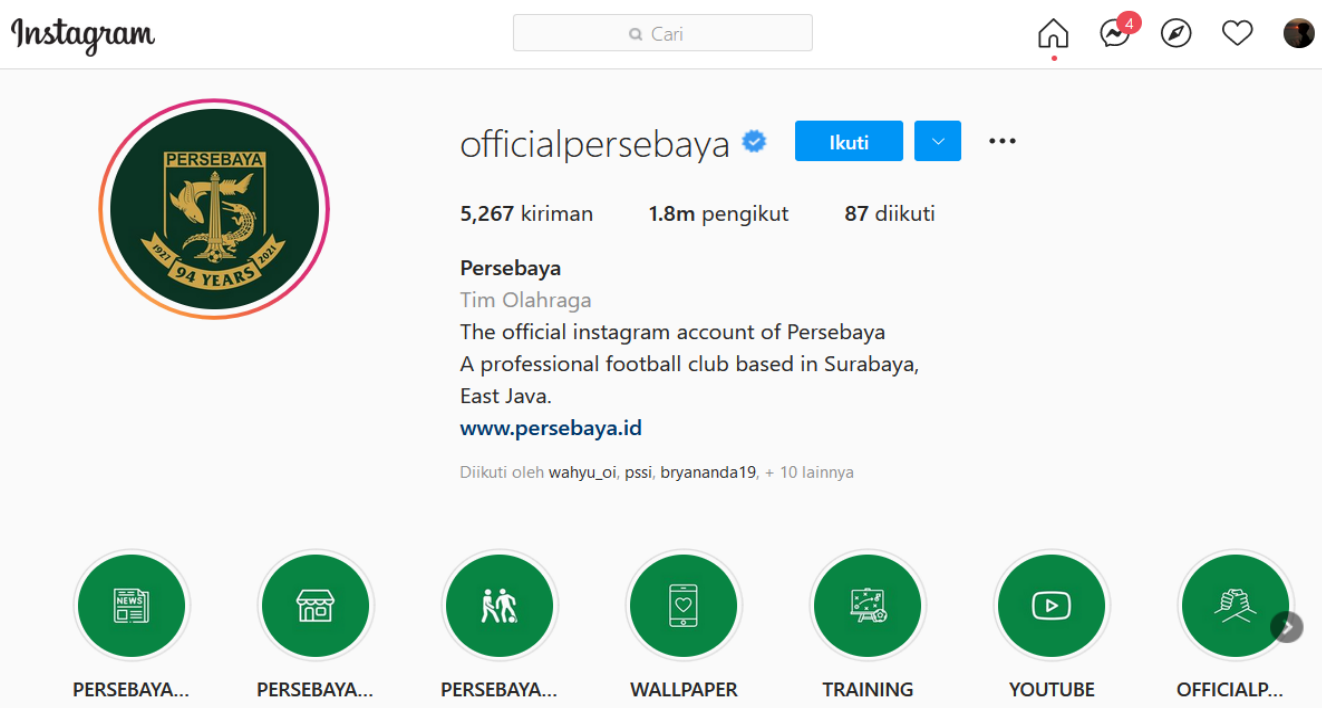

Gambar 4. Akun Instagram Persabaya Surabaya

Sumber : https:/www.instagram.com/officialpersebaya/ (akses pada 19-10-2021)

\section{Arema Fc}

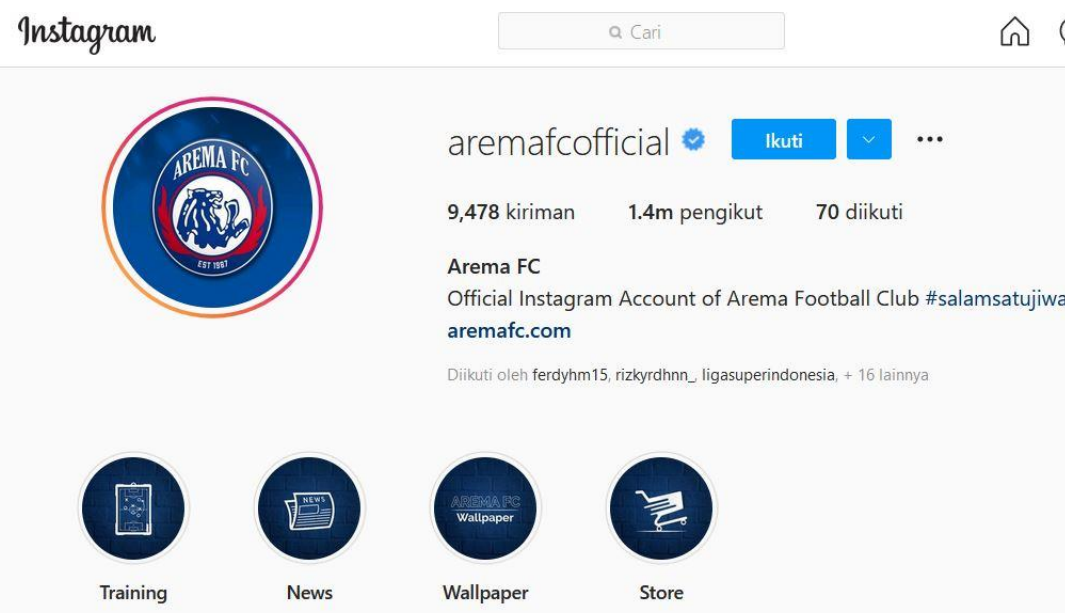

Gambar 5. Akun Instagram Arema Fc

Sumber : https:/www.instagram.com/aremaofficial/ (akses pada 19-10-2021) 


\section{Persipura Jayapura}

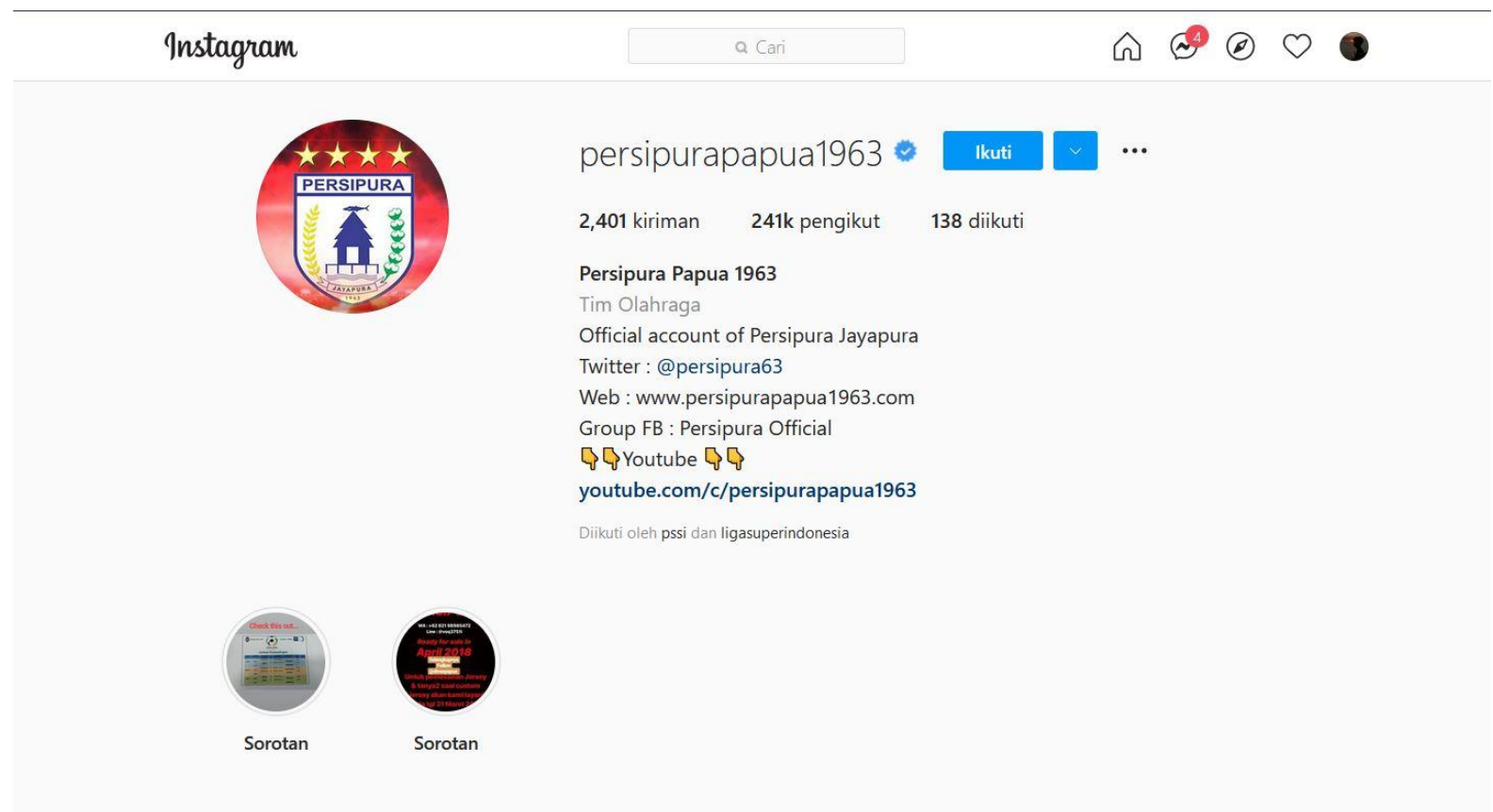

Gambar 6. Akun Instagram Persipura Jayapura

Sumber : https:/www.instagram.com/persipurapapua1963/ (akses pada 19-10-2021)

Dari kelima akun Instagram 5 Klub SepakBola Terpopuler Di Indonesia, peneliti menemukan nilai dari masing-masing variable yang ada untuk menghitung rasio Video Comments to Video Likes dari setiap akun. Pada akun Instagram terdapat 8 Variabel, diantaranya yaitu :
1. Postingan
2. Followers
3. Following
4. Video Likes
5. Video Comments
6. Video Views
7. Photo Like
8. Photo Comments

Dari 8 variabel diatas, peneliti hanya fokus untuk menemukan hasil dari 2 variabel, yaitu : 
1. Video Comments

2. Video Likes

Dari kedua variable tersebut kemudian dianalisa sehingga menemukan nilai rata-rata dari variable video comments dan variable video likes. Untuk menghitung nilai ratarata dari variable video comments dan variable video likes yaitu dengan cara mengambil 5 postingan video kemudia di hitung sehingga menemukan nilai rata-rata dari masing-masing variable. Berikut merupakan tabel nilai rata-rata dari masingmasing klub sepakbola terpopuler di Indonesia, yaitu :

Tabel 1. Analisa Nilai Rata-rata Nilai Variabel Video Comments to Video Likes Akun Instagram Persija Jakarta

\begin{tabular}{|c|r|r|}
\hline No & \multicolumn{1}{|c|}{$\begin{array}{c}\text { Video } \\
\text { Likes }\end{array}$} & \multicolumn{1}{|c|}{\begin{tabular}{c}
\multicolumn{1}{c|}{ Video } \\
Comment
\end{tabular}} \\
\hline 1 & 17.687 & 558 \\
\hline 2 & 61.151 & 185 \\
\hline 3 & 33.432 & 1.266 \\
\hline 4 & 105.612 & 307 \\
\hline 5 & 46.179 & $\mathbf{4 8 6}$ \\
\hline Total & $\mathbf{5 2 . 8 1 2}$ & \\
\hline
\end{tabular}

Sumber: Pengolahan Data Excel

Tabel 2. Analisa Nilai Rata-rata Nilai Variabel Video Comments to Video Likes Akun Instagram Persib Bandung

\begin{tabular}{|r|r|r|}
\hline No & \multicolumn{1}{|c|}{$\begin{array}{l}\text { Video } \\
\text { Likes }\end{array}$} & \multicolumn{1}{|c|}{\begin{tabular}{c}
\multicolumn{1}{c|}{ Video } \\
Comment
\end{tabular}} \\
\hline 1 & 42.725 & 478 \\
\hline 2 & 31.145 & 146 \\
\hline 3 & 56.133 & 1.746 \\
\hline 4 & 55.229 & 3.977 \\
\hline 5 & 32.240 & 3.876 \\
\hline
\end{tabular}




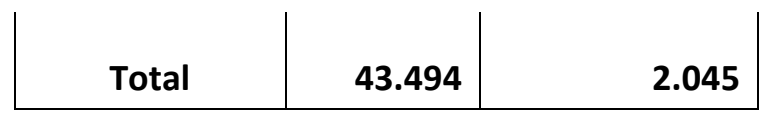

Sumber: Pengolahan Data Excel

Tabel 3. Analisa Nilai Rata-rata Nilai Variabel Video Comments to Video Likes Akun Instagram Persabaya Surabaya

\begin{tabular}{|c|r|r|}
\hline No & \multicolumn{1}{|c|}{$\begin{array}{c}\text { Video } \\
\text { Likes }\end{array}$} & \multicolumn{1}{|c|}{$\begin{array}{c}\text { Video } \\
\text { Comment }\end{array}$} \\
\hline 1 & 80.963 & 1.141 \\
\hline 2 & 35.180 & 545 \\
\hline 3 & 38.348 & 738 \\
\hline 4 & 25.755 & 419 \\
\hline 5 & 17.387 & 211 \\
\hline Total & 39.527 & 611 \\
\hline
\end{tabular}

Sumber: Pengolahan Data Excel

Tabel 4. Analisa Nilai Rata-rata Nilai Variabel Video Comments to Video Likes Akun Instagram Arema Fc

\begin{tabular}{|c|r|r|}
\hline No & \multicolumn{1}{|c|}{$\begin{array}{c}\text { Video } \\
\text { Likes }\end{array}$} & \multicolumn{2}{|c|}{$\begin{array}{c}\text { Video } \\
\text { Comment }\end{array}$} \\
\hline 1 & 25.020 & 138 \\
\hline 2 & 20.790 & 111 \\
\hline 3 & 25.663 & 285 \\
\hline 4 & 22.741 & 197 \\
\hline 5 & 18.626 & 126 \\
\hline Total & $\mathbf{2 2 . 5 6 8}$ & $\mathbf{1 7 1}$ \\
\hline
\end{tabular}

Sumber: Pengolahan Data Excel 
Tabel 5. Analisa Nilai Rata-rata Nilai Variabel Video Comments to Video Likes Akun Instagram Persipura Jayapura

\begin{tabular}{|c|r|r|}
\hline No & \multicolumn{1}{|c|}{$\begin{array}{c}\text { Video } \\
\text { Likes }\end{array}$} & \multicolumn{2}{|c|}{$\begin{array}{c}\text { Video } \\
\text { Comment }\end{array}$} \\
\hline 1 & 2.232 & 30 \\
\hline 2 & 1.783 & 20 \\
\hline 3 & 3.188 & 44 \\
\hline 4 & 2.809 & 49 \\
\hline 5 & 3.028 & 99 \\
\hline Total & $\mathbf{2 . 6 0 8}$ & $\mathbf{4 8}$ \\
\hline
\end{tabular}

Sumber: Pengolahan Data Excel

Setelah menghitung nilai rata-rata tersebut, maka akan mendapatkan hasil akhir nilai rata-rata dari variable video comments to video likes.

Tabel 6. Nilai Variabel Pada 5 Akun Instagram klub sepakbola terpopuler di Indonesia

\begin{tabular}{|l|c|c|c|c|c|}
\hline \multicolumn{1}{|c|}{ Variable } & PERSIJA JAKARTA & $\begin{array}{c}\text { PERSIB } \\
\text { BANDUNG }\end{array}$ & AREMA FC & $\begin{array}{c}\text { PERSEBAYA } \\
\text { SURABAYA }\end{array}$ & $\begin{array}{c}\text { PERSIPURA } \\
\text { JAYAPURA }\end{array}$ \\
\hline Video Likes & 52182 & 43494 & 22568 & 39527 & 2608 \\
\hline $\begin{array}{l}\text { Video } \\
\text { Comments }\end{array}$ & 486 & 2045 & 171 & 611 & 48 \\
\hline
\end{tabular}

Sumber: Pengolahan Data Excel 
Pada akun Instagram terdapat 12 rasio yang relevan digunakan untuk mengukur kredibilitas pada masing-masing akun. Namun pada penelitian kali ini hanya berfokus untuk menghitung Video Comments to Video Likes Ratio. Untuk menghitung kredibilitas dari masing-masing akun Instagram setiap klub sepakbola, peneliti menghitung dengan cara : variabel 2 akan dibagi dengan variabel 1, sehingga ditemukan hasil analisisa dari rasio tersebut.

Tabel 7. Hasil Perhitungan Rasio Akun Instagram Klub SepakBola Terpopuler Di Indonesia

\begin{tabular}{|c|c|c|c|c|c|c|}
\hline No & RATIO & $\begin{array}{l}\text { PERSIJA } \\
\text { JAKARTA }\end{array}$ & $\begin{array}{l}\text { PERSIB } \\
\text { BANDUN } \\
\text { G }\end{array}$ & $\begin{array}{l}\text { AREMA } \\
\text { FC }\end{array}$ & $\begin{array}{l}\text { PERSEBAYA } \\
\text { SURABAYA }\end{array}$ & $\begin{array}{l}\text { PERSIPUR } \\
\text { A } \\
\text { JAYAPURA }\end{array}$ \\
\hline 1 & $\begin{array}{l}\text { Video } \\
\text { Comments } \\
\text { to Video } \\
\text { Likes Ratio }\end{array}$ & $\begin{array}{l}0,0093135 \\
6\end{array}$ & 0,04701798 & $\begin{array}{l}0,0075771 \\
0\end{array}$ & 0,01545779 & 0,01840491 \\
\hline
\end{tabular}

Sumber: Pengolahan Data Excel

Video Comments to Video Likes Ratio memiliki karakteristik yang tinggi, artinya semakin tinggi nilai yang dihasilkan maka semakin baik kredibilitas dari performa akun tersebut. Untuk memberikan peringkat pada masing-masing klub sepakbola terpopuler di indonesia, peneliti memberikan angka 5 kepada vendor yang mendapatkan nilai tertinggi dan angka 1 untuk klub sepakbola terpopuler di Indonesia yang mendapatkan nilai terendah. Berikut merupakan tabel urutan nilai yang dihasilkan oleh masingmasing klub sepakbola terpopuler di indonesia.

Tabel 8. Nilai Rasio Akun Instagram klubsepak bola Terpopuler di Indonesia

\begin{tabular}{|c|c|c|c|c|}
\hline $\begin{array}{c}\text { Persija } \\
\text { Jakarta }\end{array}$ & $\begin{array}{c}\text { Persib } \\
\text { Bandung }\end{array}$ & $\begin{array}{c}\text { Arema } \\
\text { FC }\end{array}$ & $\begin{array}{c}\text { Persebaya } \\
\text { Surabaya }\end{array}$ & $\begin{array}{c}\text { Persipura } \\
\text { Jayapura }\end{array}$ \\
\hline 2 & 5 & 1 & 3 & 4 \\
\hline
\end{tabular}

Sumber: Pengolahan Data Excel 
Dari Tabel Nilai Rasio 5 Akun Instagram Terpopuler Di Indonesia dapat disimpulkan bahwa Akun Instagram Persib Bandung mendapatkan nilai tertinggi untuk rasio Video Comments to Video Likess. Sedangkan akun Instagram Arema Fc mendapatkan nilai terendah untuk rasio ini. Jadi, pada penelitian ini akun Persib Bandung memiliki kredibilitas performa yang lebih baik dibandingkan dengan akun klub sepakbola yang lainnya. 


\section{KESIMPULAN}

Tujuan dari penelitian ini adalah mengetahui kredibilitas performa dari akun Instagram 5 Klub SepakBola Terpopuler di Indonesia menggunakan Video Comments to Video Likess Ratio. 5 Klub SepakBola Terpopuler Di Indonesia tersebut, yaitu : Persija Jakarta, Persib Bandung, Arema Fc, Persebaya Surabaya, Persipura Jayapura. Dari Kelima Klub SepakBola tersebut dapat disimpulkan bahwa :

1. Peringkat pertama diraih oleh klub Persib Bandung dengan nilai tertinggi yaitu 0,04701798 .

2. Peringkat kedua diraih oleh klub Persipura Jayapura dengan nilai 0,01840491.

3. Peringkat ketiga diraih oleh klub Persebaya Surabaya dengan nilai 0,01545779

4. Peringkat keempat diraih oleh klub Persija Jakarta dengan nilai 0,00931356

5. Peringkat kelima diraih oleh Arema Fc dengan nilai terendah yaitu 0,00757710 


\section{DAFTAR PUSTAKA}

“AFC Sebut 5 Klub Terpopuler Di Indonesia, Ada Persija Dan Persib? - Semua Halaman Bolasport.Com.” n.d. Accessed October 27, 2021.

https://www.bolasport.com/read/312281931/afc-sebut-5-klub-terpopuler-di-indonesiaada-persija-dan-persib?page $=$ all.

Agianto, Rifqi, Anggi Setiawati, and Ricky Firmansyah. 2020. "Pengaruh Media Sosial Instagram Terhadap Gaya Hidup Dan Etika Remaja.” TEMATIK - Jurnal Teknologi Informasi Dan Komunikasi 7 (2 SE-Articles): 130-39. https://jurnal.plb.ac.id/index.php/tematik/article/view/461.

Ayutiani, Difa Nurhasna, and Berlian Primadani Satria Putri. 2018. "Penggunaan Akun Instagram Sebagai Media Informasi Wisata Kuliner.” PRofesi Humas : Jurnal Ilmiah Ilmu Hubungan Masyarakat 3 (1): 39. https://doi.org/10.24198/prh.v3i1.11683.

Hendika Permana, I Putu. 2021. "Analisis Rasio Pada Instagram Untuk Penelitian Kualitatif Menggunakan Metode Ekploratif.” Jurnal Ilmiah Media Sisfo 15 (1): 40. https://doi.org/10.33998/mediasisfo.2021.15.1.970.

"Inilah Negara Pengguna Instagram Terbanyak, Indonesia Urutan Berapa?|Databoks.” n.d. Accessed October 27, 2021.

https://databoks.katadata.co.id/datapublish/2021/08/03/inilah-negara-penggunainstagram-terbanyak-indonesia-urutan-berapa.

Jiwantono, Jordan, Listia Natadjaja, and DANIEL KURNIAWAN SALAMOON. 2021. "Perancangan Desain Konten Sosial Media Tentang Sepak Bola Melalui Instagram Dengan Berbasis Microblog.” Jurnal DKV Adiwarna 1 (18): 10.

"Penelitian Eksploratif - Wikipedia Bahasa Indonesia, Ensiklopedia Bebas." n.d. Accessed October 27, 2021. https://id.wikipedia.org/wiki/Penelitian_eksploratif\#cite_refPenelitian_1-0. 